\title{
Safety Evaluation of Stop-Sign Mounted Beacons-A Cross-Sectional Study
}

\author{
Amrita Goswamy1 ${ }^{(1)}$, Shauna Hallmark ${ }^{*}{ }^{\circledR}$, Guillermo Basulto-Elias², Michael Pawlovich ${ }^{3}$ \\ ${ }^{1}$ Department of Civil, Construction, and Environmental Engineering, Iowa State University, Ames, USA \\ ${ }^{2}$ Center for Statistics and Applications in Forensic Evidence, Iowa State University, Ames, USA \\ ${ }^{3}$ Jerome J. Lohr College of Engineering, South Dakota State University, Brookings, USA \\ Email: agoswamy@iastate.edu, ^shallmar@iastate.edu, basulto@ia state.edu, Michael.Pawlovich@sdstate.edu
}

How to cite this paper: Goswamy, A., Hallmark, S., Basulto-Elias, G. and Pawlovich, M. (2019) Safety Evaluation of StopSign Mounted Beacons-A Cross-Sectional Study. Journal of Transportation Technologies, 9, 95-108.

https://doi.org/10.4236/jtts.2019.91006

Received: November 29, 2018

Accepted: January 8, 2019

Published: January 11, 2019

Copyright (c) 2019 by author(s) and Scientific Research Publishing Inc. This work is licensed under the Creative Commons Attribution International License (CC BY 4.0).

http://creativecommons.org/licenses/by/4.0/

\begin{abstract}
Agencies in Iowa have utilized both overhead flashing beacons and stop-sign mounted beacons. Although several studies have shown that overhead flashing beacons are effective, some concerns have been raised about driver confusion. The main concern is that a driver may interpret a multiface flashing beacon with a red indication for their approach as an all-way stop control. As a result, the Iowa DOT has been advocating use of stop-sign mounted beacons rather than overhead flashing beacons. Since little information is available about this countermeasure, data for intersections with (treatment) and without (control) stop-sign mounted beacons were identified and a cross-sectional analysis conducted (due to few confirmable installation dates). Rural stop-controlled intersections with stop-sign mounted beacons in Iowa (USA) were identified (40 in total). Intersection characteristics such as number of approaches, intersection angle etc. were extracted. Additionally, characteristics of individual approaches such as roadway surface (gravel/paved), advanced stop-sign rumble strips, and advance signing were recorded. One or more control locations were manually selected for each treatment intersection based on matching roadway configuration, presence of lighting, advance stop line rumble strips, number of approaches, channelization, traffic volume, and proximity. Propensity scores were estimated to match 40 control locations for comparison. Negative binomial models for different injury combinations at nighttime and daytime were developed with an indicator variable for presence and absence of stop-sign mounted beacons. Presence of stop-sign mounted beacons was associated with a $5 \%-54 \%$ reduction in nighttime crashes. Injury nighttime crashes decreased by $54 \%$ and total nighttime crashes reduced by $18 \%$.
\end{abstract}

\section{Keywords}

Stop-Sign Mounted Beacons, Safety Analysis, Nighttime Crashes, 


\section{Introduction}

Rural intersections account for $16 \%$ of fatalities in rural areas [1]. Rural intersection crashes are frequently a result of driver's failing to yield right of way (FTYROW). Failure to yield may be due to speeding which can result in failure to react in time or may be due to failure to recognize the presence of the intersection or traffic control due to sight distance issues or driver inattention. Retting et al. [2] investigated crashes at stop-controlled intersections in four cities. They found that stop-sign violations accounted for about $70 \%$ of crashes.

Both older and younger drivers have been attributed responsibility in failure to yield crashes at intersections. Retting et al. [2] report that younger drivers $(<18)$ and older driver $(65+)$ were more likely to be at fault at crashes at stop controlled intersections. Massie et al. [3] created a collision typology to assess crash types. They investigated 50 crashes involving failure to yield. They found older drivers were more likely to stop first and then pull out and collide with another vehicle while younger drivers were more likely to not stop. Intersection characteristics such as sight distance, skew angle, presence of horizontal or vertical curvature, presence of median, or lighting have also been correlated to failure to yield and intersection crash risk [4] [5] [6].

Beacons are one countermeasure that have been utilized to reduce rural intersection crash risk. Beacons draw attention to the presence of the intersection and/or traffic control encouraging improved driver response. The different types of beacons include intersection control beacons mounted over the intersection (also referred to as overhead flashing beacons), standard stop-sign mounted beacons, and actuated flashing beacons (typically placed on the stop-sign but actuate only when speed is over a certain threshold).

\subsection{Studies on Effectiveness of Overhead Flashing Beacons}

The most common intersection beacon configuration is overhead flashing beacons which flash red to drivers with stop controlled approaches and yellow for major road approaches (non-stop). Several studies have evaluated overhead flashing beacons and in general they have been shown to reduce crashes. However, some concern has been expressed that drivers are confused by overhead flashing beacons and in some cases, believe they indicate an all-way stop.

Srinivasan et al. [7] evaluated the impact of flashing beacons at stop-controlled intersections in North and South Carolina. Several types of beacons were studied including overhead flashing beacons ( 84 treatments sites). A before and after EB method was used to study the safety effectiveness. They found an $11.9 \%$ reduction in angle crashes.

Murphy and Hummer [8] evaluated overhead flashing beacons at 34 four-leg, two-way stop-controlled rural intersections in North Carolina. They used an EB 
analysis method which accounted for changes in traffic volume. They found a $12 \%$ decrease in total crashes, a $9 \%$ decrease in injury crashes, a $40 \%$ decrease in severe injury crashes, a $9 \%$ decrease in frontal impact crashes, and a $26 \%$ reduction in "ran stop-sign" crashes.

Pant et al. [9] performed a comparative study with rural overhead beacon controlled and similar stop controlled intersections located in rural areas of Ohio. A before-and-after analysis was performed by comparing the 2 to 3 years of crash and traffic volume data at seven two-way beacon-controlled intersections. It was found that beacons reduced vehicular speeds in the major directions of traffic, especially at intersections with inadequate stopping sight distance. However, the beacons were found to have little effect on accepted or rejected gaps and were ineffective in reducing stop-sign violations. They also found no statistically significant reduction in crashes.

Hammer et al. [10] evaluated the before and after accident record to study the safety effectiveness of overhead yellow-red beacons (14 two-way stop controlled intersections) and red-red beacons (10 all-way stop controlled intersections) in California. The study reported reduction in right angle crashes at all four-leg intersections regardless of type of flasher but results were not statistically significant. Fatal crashes were not significantly reduced when a flashing beacon was installed.

A North Carolina study by Cribbins [11] evaluated the effectiveness of traffic signals and overhead flashers at rural intersections in reducing crashes. For the study, they analyzed crash experience at 14 rural intersections where flashing beacons were installed. A one year before and after study was conducted. Overall, it was found a $62 \%$ decrease in single-vehicle crashes and a $21 \%$ reduction in multiple vehicle crashes for the installation of overhead flashing beacons.

Brewer and Fitzpatrick [12] investigated various treatments for rural highways and intersections in Texas by analyzing crash data before and after installation of the measures. They evaluated four intersections where flashing overhead beacons were installed and found that the crash rate was reduced by $43 \%$ from the period of three years before to three years after the improvement was installed.

Stackhouse and Cassidy [13] studied the safety effects of overhead warning beacons at rural intersections. They analyzed crash data at twelve rural intersections of Minnesota for three years before and after period of installation of the beacons. All were four-way with stop control on the minor approaches. After installation of overhead flashers at eight intersections, a 39\% reduction in crashes was observed. A driver opinion survey showed that both overhead and sign-mounted flashing beacons warned drivers that an intersection was potentially more dangerous. Driver's opinion also indicated that they were more likely to prepare to stop encountering a red flasher than a yellow flasher. Drivers said that they were more likely to stop in the presence of red overhead flashing beacons compared to a pedestal-mounted red flasher on stop-sign. More than half of the respondents both young and old stated that flashers were very useful at 
night. Approximately half of the drivers stated that they were confused about the meaning of the flashing lights.

\subsection{Studies on Standard Stop-Sign Beacons}

Standard stop-sign beacons are usually mounted on a stop-sign. In some cases, there may be a warning beacon upstream. Srinivasan et al. [7] evaluated the impact of flashing beacons at stop-controlled intersections in North and South Carolina. Several types of beacons were studied including standard stop-sign mounted flashing beacons which were evaluated for 5 treatment sites. A before and after EB method was used to study the safety effectiveness. They found a $58.2 \%$ reduction in angle crashes.

Janoff et al. [14] studied the effectiveness of stop-sign mounted flashing beacons in reducing crashes at hazardous rural curves. Crash data for a 2 year before and after period were analyzed for a rural highway curve in Texas that had been treated with a single flashing beacon. The analysis showed a $50 \%$ reduction in total accidents. The benefit-cost ratio was found to be in excess of 50:1 for the flashing beacon installation.

Brewer and Fitzpatrick [12] investigated various treatments for rural highways and intersections. They found that a flashing beacon mounted on a "STOP AHEAD" sign for a single intersection had a crash reduction from 0.06 to 0.03 crashes/month for the three years before and three years after installation.

\subsection{Problem Statement}

Agencies in Iowa have utilized both overhead flashing beacons and stop-sign mounted beacons. Though overhead flashing beacons are currently the predominant type, they are being replaced through a state-funded program. Although several studies have shown that overhead flashing beacons are effective, some concern that the countermeasure may cause driver confusion exists. When a driver along a minor stop-controlled approach encounters an overhead flashing beacon with multiple faces, they may falsely interpret the red flashing beacon to be displayed for all approaches indicating all-way stop control. In this situation, even when the driver comes to a complete stop, they may erroneously assume oncoming traffic will stop. Overhead flashing beacons also require some type of overhead support structures, typically span wires run from poles.

For both reasons, the Iowa DOT is advocating use of stop-sign mounted beacons rather than overhead flashing beacons. Since little information is available about this countermeasure, data for intersections with (treatment) and without (control) stop-sign mounted beacons were identified and a cross-sectional analysis conducted. A cross-sectional study was conducted due to few confirmable installation dates.

\section{Data}

The Institute of Transportation (InTrans) and the Iowa DOT developed an in- 
tersection database for the state of Iowa for a previous project. Intersection location on most public roadways were identified and characteristics collected. These included types of traffic control (i.e. stop, yield, and signal), presence of overhead lighting, and many others. Intersections are spatially located and can be queried in ArcMap so that intersections with characteristics of interest can be identified.

Presence of beacons was not specifically included as a feature of interest. However, an indication of beacon presence was frequently indicated in the notes section. The notes field was searched for key words such as "flashing" or "beacon" and then intersections with potential beacons were flagged. Next Google Street View was consulted and presence of stop-sign mounted beacons was confirmed. A total of 40 intersections with at least one stop-sign mounted beacon were identified.

Once an initial set of locations was identified, additional data elements not included in the intersection database, such as presence of turn lanes, were extracted from other sources such as Google Street view, Microsoft Birdseye, Google Aerial View, and Bing Maps. Google street view was also used to confirm that the sites were devoid of any other advance warning signs besides the flashing beacons. Approach data were aggregated for each of the intersections depending upon the number of approaches associated with an intersection. For example, a combined indicator variable was created for the intersections that had paved major road and gravel/unpaved minor road approaches. Another combined indicator variable designated an intersection of two-way major road and one-way minor road approaches. The intersection approach dataset contained information on pavement surface, number of approach lanes, number of exclusive left/right turn lanes, left turn type, presence of right channelization, traffic control, crosswalk type, type of median and advance stop-sign rumble strips.

Once a set of intersections with stop-sign mounted beacons was identified, the corresponding Iowa agency (county engineers or DOT District offices) were consulted to confirm presence and acquire installation dates. However, most agencies did not retain records of beacon installation dates. As a result, a standard before and after analysis, whether naive or empirical Bayes, was not possible. Instead a cross-sectional study was conducted. To facilitate the cross-sectional analysis, due to the unconfirmed installation dates, data for a particular intersection were only included when presence of a stop-sign mounted beacon was confirmed during a particular period. For instance, if presence was confirmed starting in 2008, data was included for 2008 forward. When installation date was known, that date was used as the starting point. In other cases, the date where an image was available to confirm presence of a beacon was used. For instance, if a Google Street View image showed a beacon in 2008, this became the assumed starting date. Starting dates varied from 2008 to 2012.

Control locations were selected for each treatment intersection. The first step 
in identifying candidates was to check intersections surrounding the treatment intersection. Several key features were used to select a control intersection which include:

1) Roadway configuration (i.e., 4-lane/2-lane stop control; 2-lane/2-lane stop control)

2) Presence of lighting

3) Presence of advance stop line rumble strips

4) Number of approaches

5) Channelization

6) Traffic volume

7) Proximity to treatment intersection (within 1000 feet maximum)

In most cases, the first four criteria were matched for treatment and control intersections. In a few circumstances, more than one control intersection was manually identified for a treatment intersection. Intersection and approach characteristics were also extracted for control intersections using the methodology detailed for treatment intersections.

A propensity score matching technique was used to select control sites that were as similar as possible to treatment sites. This technique was similar to that used in another study where the methodology is explained in more detail (Goswamy et al. [15]). A total of 40 controls were selected to match the 40 treatment sites. The statistical software " $\mathrm{R}$ " was used to generate the propensity scores for the project. The "MatchIt" package was used to conduct propensity score matching. The data set was set up in a way such that it consisted of cases in rows and variables in columns. Nearest neighbor technique was used to match the cases. This technique matches a treated unit to a control unit(s) that is closest in terms of a distance measure. Figure 1 shows the distribution of propensity scores of matched treated and control sites. The matched sites have similar propensity scores.

The Iowa Department of Transportation (Iowa DOT) maintains a roadway inventory, the Geographic Information Management System (GIMS), database which was used to obtain the traffic volume data for each of the approach roadways for the intersections. Average annualized daily traffic (AADT) was available for every approach. Average minor and major road AADTs were calculated for each intersection.

\section{Crash Data}

The Iowa Department of Transportation (DOT) collects spatial location of all reported crashes within the state. Crashes occurring within 250 feet of each intersection, as per standard Iowa practice, were obtained for years 2012 through 2014 (five years). Crash severity levels were designated according to the KABCO scale (HSIPM, 2010) and existent within the Iowa crash data as follows: Fatal Injury Crashes (K), Disabling Injury Crashes (A), Visible Injury Crashes (B), Possible Injury Crashes (C), and Property Damage Only (PDO). However, as 


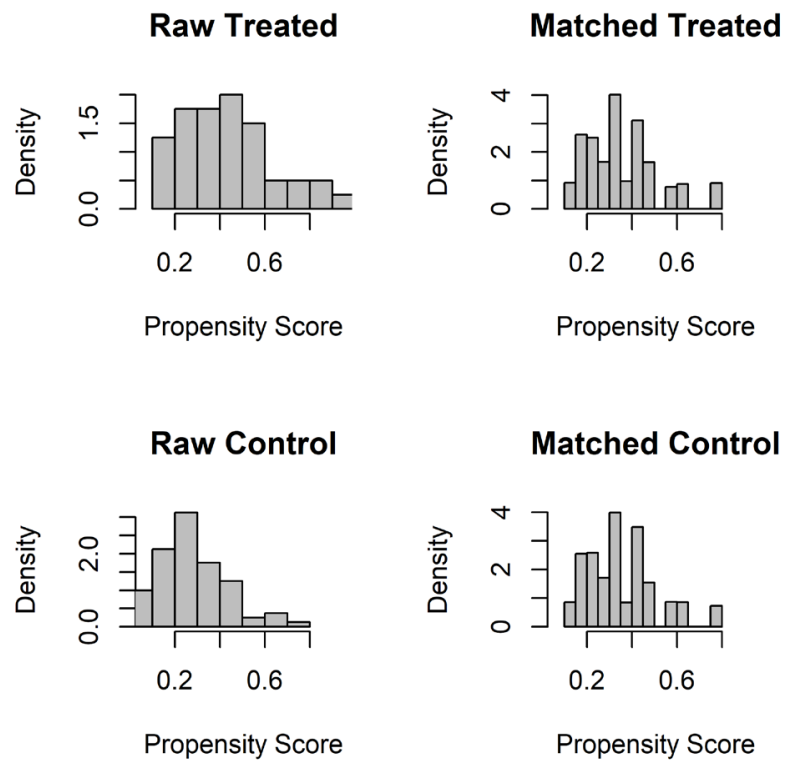

Figure 1. Propensity Score distribution of matched data.

noted in the previous section, data for treatment intersections were only included for years when presence of beacon was confirmed.

Time of day was indicated in the crash data base. Crashes coded as dusk, dawn, unknown, or non-reported crashes were not included in the study. As a result, only crashes noted as "Daylight" were included as day crashes. Crashes noted as "dark-roadway lighted", "dark-roadway not lighted”, or "dark-lighting unknown" were considered as nighttime crashes. Roadway and traffic characteristics included in the analysis are shown in Table 1. Separate summaries are provided for treatment and control sites. Some of the variables such as number of legs and traffic control were combined into single variable. For example, 3-legged all way stop or 4-legged minor road stop. It can be seen from Table 1 that the daytime crashes at the treatment sites are more compared to the control sites. However, the nighttime crashes are less for the treatment sites compared to controls especially for the injury crashes.

\section{Methodology and Results}

Ideally a before and after analysis would have been conducted. However, as noted in the Data section, most agencies did not retain records of beacon installation dates. As a result, a standard before and after analysis, whether naive or $\mathrm{EB}$, was not possible. Instead, we chose to conduct a cross-sectional analysis, which is an acceptable alternative when before data or known before periods are lacking. A cross-sectional analysis involves comparison of the safety (crash) performance at a set of treatment sites against a set of comparable control sites. Essentially, the before and after reduction is replaced with the assumption that reductions at comparable treatment and comparable control sites would be equivalent other than the effect of the treatment. Thus, if the reduction at the 
Table 1. Descriptive statistics for the control and treatment data.

\begin{tabular}{|c|c|c|c|c|c|c|c|c|c|c|}
\hline \multirow[b]{2}{*}{ Variables } & \multicolumn{6}{|c|}{ TREATMENT } & \multicolumn{4}{|c|}{ CONTROL } \\
\hline & Sum & Mean & Std. Dev & Min & $\operatorname{Max}$ & Sum & Mean & Std. Dev & Min & $\operatorname{Max}$ \\
\hline Day KABCO & 162 & 4.05 & 5.22 & 0 & 23 & 108 & 2.70 & 3.69 & 0 & 14 \\
\hline Day PDO & 97 & 2.43 & 2.97 & 0 & 11 & 61 & 1.53 & 1.84 & 0 & 7 \\
\hline Day KABC & 65 & 1.63 & 2.51 & 0 & 12 & 47 & 1.18 & 2.02 & 0 & 8 \\
\hline Night PDO & 42 & 1.05 & 1.43 & 0 & 4 & 43 & 1.08 & 0.86 & 0 & 3 \\
\hline Night KABC & 8 & 0.20 & 0.69 & 0 & 4 & 18 & 0.45 & 0.55 & 0 & 2 \\
\hline Night KABCO & 50 & 1.25 & 1.55 & 0 & 4 & 61 & 1.53 & 1.01 & 0 & 4 \\
\hline Average minor AADT & & 695.35 & 676.55 & 10 & 3180 & & 694.10 & 700.97 & 10 & 2910 \\
\hline Average major AADT & & 4959.75 & 4757.60 & 800 & 19,500 & & 4801.10 & 4230.28 & 520 & 15,000 \\
\hline Advanced rumble strips & & 0.08 & 0.27 & 0 & 1 & & 0.03 & 0.16 & 0 & 1 \\
\hline Exclusive Left Turn lanes & & 0.23 & 0.42 & 0 & 1 & & 0.33 & 0.47 & 0 & 1 \\
\hline Exclusive Right Turn lanes & & 0.18 & 0.38 & 0 & 1 & & 0.15 & 0.36 & 0 & 1 \\
\hline 3 leg all way stop & & 0.03 & 0.16 & 0 & 1 & & 0.05 & 0.22 & 0 & 1 \\
\hline 3 leg minor road stop & & 0.20 & 0.41 & 0 & 1 & & 0.45 & 0.50 & 0 & 1 \\
\hline 4 leg all way stop & & 0.23 & 0.42 & 0 & 1 & & 0.10 & 0.30 & 0 & 1 \\
\hline 4 leg minor road stop & & 0.55 & 0.50 & 0 & 1 & & 0.40 & 0.50 & 0 & 1 \\
\hline All paved approach & & 0.68 & 0.47 & 0 & 1 & & 0.38 & 0.49 & 0 & 1 \\
\hline 2 lane major one lane minor road & & 0.03 & 0.16 & 0 & 1 & & 0.03 & 0.16 & 0 & 1 \\
\hline 2 lane major 2 lane minor road & & 0.75 & 0.44 & 0 & 1 & & 0.70 & 0.46 & 0 & 1 \\
\hline 4 lane major 2 lane minor road & & 0.23 & 0.42 & 0 & 1 & & 0.28 & 0.45 & 0 & 1 \\
\hline Two way road & & 0.98 & 0.16 & 0 & 1 & & 0.98 & 0.16 & 0 & 1 \\
\hline Undivided & & 0.75 & 0.44 & 0 & 1 & & 0.68 & 0.47 & 0 & 1 \\
\hline Flushed/raised median & & 0.05 & 0.22 & 0 & 1 & & 0.05 & 0.22 & 0 & 1 \\
\hline Depressed median & & 0.20 & 0.41 & 0 & 1 & & 0.28 & 0.45 & 0 & 1 \\
\hline Crosswalk present & & 0.50 & 1.20 & 0 & 4 & & 0.38 & 0.90 & 0 & 4 \\
\hline Interchange related & & 0.03 & 0.16 & 0 & 1 & & 0.03 & 0.16 & 0 & 1 \\
\hline Intersection angle & & 83.75 & 10.55 & 35 & 90 & & 85.49 & 8.04 & 59 & 90 \\
\hline Destination light & & 0.40 & 0.50 & 0 & 1 & & 0.33 & 0.47 & 0 & 1 \\
\hline Intersection light & & 0.35 & 0.48 & 0 & 1 & & 0.25 & 0.44 & 0 & 1 \\
\hline
\end{tabular}

treatment sites differs from the control sites, the difference can be assumed to be due to the treatment.

A simple statistical comparison indicated that crashes during the nighttime at treatment sites were disproportionately lower than control sites. As a result, daytime crashes were used as measure of exposure and the impact of beacons on nighttime crashes was investigated. Comparing the ratio of night to day crashes has been widely used to estimate the impact of street lighting. Jackett and Frith 
[16] and others [17] [18] used the night-time to day-time crash ratio to assess road luminance. Donnell et al. [19] utilized a similar method to compare across lighting studies. Night-to-day crash ratios was used to evaluate the safety effects of roadway lighting. The night to day crash ratios were calculated for treatment and control intersections. The night to day crash ratio for treatment sites with stop-sign mounted beacons was 0.31 while the ratio for control sites was 0.56 . This indicates around 0.31 nighttime crashes result for every day crash at treatment sites while around 0.56-night crashes occur at control sites for every day crashes. As a result, this simple comparison shows that the ratio of night to day crashes at treatment sites is $25 \%$ lower than for control sites.

\section{Cross-Sectional Models}

Cross-sectional crash models using negative binomial generalized linear regression analysis were developed with an indicator variable for presence and absence of stop-sign mounted beacons. All models were fit using statistical software $\mathrm{R}$. The negative binomial model specification estimates the probability $f\left(y_{i}\right)$ of $y_{i}$ crashes occurring on segment $i$ using gamma function as shown in Equation (1):

$$
f\left(y_{i}\right)=\frac{\Gamma\left(y_{i}+\phi\right)}{\Gamma\left(y_{i}+1\right) \Gamma(\phi)}\left(\frac{\phi}{\phi+\mu_{i}}\right)^{\phi}\left(\frac{\mu_{i}}{\phi+\mu_{i}}\right)^{y_{i}}
$$

where,

$\phi$ is the inverse dispersion factor, $\phi=\frac{1}{\alpha}, \alpha=$ over dispersion factor.

If $\alpha$ is significantly greater than zero, the data are over dispersed. Thus the mean and variance are given by Equation (2) and (3):

$$
\begin{gathered}
E\left(y_{i}\right)=\mu_{i}=\exp \left(\beta X_{i}+\varepsilon_{i}\right) \\
\operatorname{Var}\left(y_{i}\right)=\mu_{i}+\frac{\mu_{i}^{2}}{\phi} \text { or } \operatorname{Var}\left(y_{i}\right)=\mu_{i}+\alpha \mu_{i}^{2}
\end{gathered}
$$

where,

$\mu_{i}=$ expected number of crashes at location $i$

$\beta=$ vector of estimable regression parameters;

$X_{i}=$ vector of geometric design and traffic volume explanatory variables for location $i$

$\varepsilon_{i}=$ gamma-distributed error term.

Elasticities for continuous variables like AADT and pseudo elasticities in the form of percentages for indicator variables in the model was calculated according to a study by Donnell et al. [19]. The elasticities computed based on the daytime and nighttime crash frequency models shown in Table 2 are provided in Table 3.

Separate models for nighttime and daytime crashes were evaluated. The parameter estimates, standard errors of the statistically significant variables (at $90 \%$ confidence level) in the cross-sectional models and the goodness of fit of each of the crash models are shown in Table 2. The standard errors and p-values are 
Table 2. Daytime and nighttime crash frequency models.

\begin{tabular}{|c|c|c|c|c|c|c|c|}
\hline & & \multicolumn{3}{|c|}{ Daytime } & \multicolumn{3}{|c|}{ Nighttime } \\
\hline & & Estimate & Std. error & $P$ values & Estimate & Std. error & $P$ values \\
\hline \multirow{7}{*}{ KABCO } & (Intercept) & -8.053 & 1.143 & $0.000^{*}$ & -4.710 & 0.902 & $0.000^{*}$ \\
\hline & Treatment & 0.304 & 0.206 & 0.146 & -0.198 & 0.160 & 0.219 \\
\hline & Ln Average Minor AADT & 0.229 & 0.085 & $0.008^{\star}$ & 0.015 & 0.057 & 0.793 \\
\hline & Ln Average Major AADT & 0.900 & 0.125 & $0.000^{\star}$ & 0.613 & 0.099 & $0.000^{*}$ \\
\hline & Advanced Rumble Strips & 1.002 & 0.467 & $0.035^{*}$ & -1.079 & 0.851 & 0.209 \\
\hline & Crosswalk present & na & na & na & -0.276 & 0.140 & $0.052^{*}$ \\
\hline & AIC & 329.840 & & & 212.920 & & \\
\hline \multirow{8}{*}{$\mathrm{KABC}$} & (Intercept) & -6.495 & 1.409 & $0.000^{*}$ & -7.620 & 2.444 & $0.003^{*}$ \\
\hline & Treatment & 0.032 & 0.274 & 0.906 & -0.778 & 0.439 & 0.080 \\
\hline & Ln Average Minor AADT & 0.231 & 0.115 & $0.049^{*}$ & -0.089 & 0.132 & 0.501 \\
\hline & Ln Average Major AADT & 0.691 & 0.155 & $0.000^{\star}$ & 0.864 & 0.260 & $0.001^{*}$ \\
\hline & 3 leg minor road stop & -1.129 & 0.331 & $0.001^{*}$ & na & na & na \\
\hline & 4 leg all way stop & -0.714 & 0.500 & 0.158 & 1.110 & 0.803 & 0.171 \\
\hline & Crosswalk present & -0.534 & 0.275 & $0.056^{*}$ & & & \\
\hline & AIC & 228.200 & & & 111.380 & & \\
\hline \multirow{7}{*}{ PDO } & (Intercept) & -8.513 & 1.078 & $0.000^{*}$ & -5.899 & 1.143 & $0.000^{*}$ \\
\hline & Treatment & 0.382 & 0.179 & 0.036 & -0.050 & 0.211 & 0.815 \\
\hline & Ln Average Minor AADT & 0.254 & 0.077 & $0.002^{\star}$ & 0.039 & 0.078 & 0.618 \\
\hline & Ln Average Major AADT & 0.875 & 0.118 & $0.000^{\star}$ & 0.686 & 0.124 & $0.000^{*}$ \\
\hline & Advanced Rumble Strips & 0.778 & 0.470 & 0.102 & na & na & na \\
\hline & 4 leg all way stop & -0.444 & 0.312 & 0.159 & na & na & na \\
\hline & AIC & 251.080 & & & 203.240 & & \\
\hline
\end{tabular}

Note: ${ }^{*}$ indicate significance at $1 \%$ or $5 \%$ or $10 \%$ levels.

also provided for the parameter estimates or in other words beta estimates in Table 2. The Akaike information criterion (AIC) was used to estimate model fit and is also provided in Table 2. AIC value was used to compare the performances of the GLMs. The preferred model is the one with the minimum AIC value. The AIC value can be evaluated using:

$$
\mathrm{AIC}=2 k-2 \ln (L)
$$

where, $k=$ The number of estimated parameters in the model; $L=$ The maximum value of the likelihood function for the model.

The elasticities for major and minor road traffic volumes were similar across all the nighttime and daytime crash frequency models except for nighttime injury crash model. In both cases, however, the nighttime elasticities are lower than the daytime elasticities, and the minor road elasticities are lower than the major road elasticities. A 1\% increase in major road average AADT is associated 
Table 3. Elasticities for daytime and nighttime crash frequencies.

\begin{tabular}{|c|c|c|c|}
\hline & & \multicolumn{2}{|c|}{ ELASTICITY OR PSEUDO ELASTICITY (\%) } \\
\hline & Variables & Daytime Crashes & Nighttime Crashes \\
\hline \multirow{5}{*}{$\begin{array}{c}\text { KABCO } \\
\text { (Total) }\end{array}$} & Treatment & $35 \%$ & $-18 \%$ \\
\hline & Ln Average Minor AADT & 0.229 & 0.015 \\
\hline & Ln Average Major AADT & 0.900 & 0.613 \\
\hline & Advanced Rumble Strips & $172 \%$ & $-66 \%$ \\
\hline & Crosswalk present & na & $-24 \%$ \\
\hline \multirow{6}{*}{$\begin{array}{l}\text { KABC } \\
\text { (Injury } \\
\text { Crashes) }\end{array}$} & Treatment & $3 \%$ & $-54 \%$ \\
\hline & Ln Average Minor AADT & 0.231 & -0.089 \\
\hline & Ln Average Major AADT & 0.691 & 0.864 \\
\hline & 3 leg minor road stop & $-68 \%$ & na \\
\hline & 4 leg all way stop & $-51 \%$ & $204 \%$ \\
\hline & Crosswalk present & $-41 \%$ & na \\
\hline \multirow{5}{*}{$\begin{array}{c}\text { PDO } \\
\text { (Property } \\
\text { Damage } \\
\text { Only) }\end{array}$} & Treatment & $46 \%$ & $-5 \%$ \\
\hline & Ln Average Minor AADT & 0.254 & 0.039 \\
\hline & Ln Average Major AADT & 0.875 & 0.686 \\
\hline & Advanced Rumble Strips & $118 \%$ & na \\
\hline & 4 leg all way stop & $-36 \%$ & na \\
\hline
\end{tabular}

with an approximate $0.7 \%$ to $0.7 \%$ increase in crash frequency. A $1 \%$ increase in minor road average AADT is associated with an increase in the daytime and nighttime crash frequency of $0.2 \%$ to $0.7 \%$ approximately. This finding indicates that the major road traffic volume has a greater effect on intersection crashes than the minor road traffic volume. These results are in line with previous studies (Donell et al. [19]).

It was seen that the treatment elasticities changes sign when comparing the expected daytime and nighttime crash frequencies across all models. This suggests that the locations with stop-sign mounted beacons have $3 \%-46 \%$ more daytime crashes across all severity models. This makes sense as beacons are usually installed at high crash locations. Locations with beacons are also associated with a $5 \%-54 \%$ reduction in nighttime crashes. More desirably injury nighttime crashes decreased by $54 \%$ (statistically significantly at 0.1 alpha level) and total nighttime crashes reduced by $18 \%$. Property damage crashes were reduced by $5 \%$. These results signify that the treatment have potential for decreasing severe crashes. Advanced stop-sign rumble strips did not have any positive effect on daytime total and property damage only crashes. However, advanced stop-sign rumble strips reduced total nighttime crashes by $66 \%$. It did not significantly affect nighttime PDO and injury crashes. Presence of crosswalk reduced total nighttime crashes $24 \%$ and injury daytime crashes by $41 \%$. Four legged, all way stop controlled intersections were associated with $36 \%$ less day- 
time crashes.

\section{Conclusions and Discussions}

This study examined the safety effectiveness of stop-sign mounted beacons in Iowa. Various factors affecting the frequency of crashes were analyzed. Propensity score matching technique was used to match treatment and control sites in this study. The study developed crash frequency models for several injury combinations for nighttime and daytime crashes with AADTs of minor and major roads at approaches with stop-sign mounted beacons. Elasticities were calculated from these models as well.

A cross-sectional study was conducted since agencies did not retain installation dates. A cross-sectional analysis involves comparison of the safety (crash) performance at a set of treatment sites against a set of comparable control sites. Essentially, the before and after reduction is replaced with the assumption that reductions at comparable treatment and comparable control sites would be equivalent other than the effect of the treatment. Thus, if the reduction at the treatment sites differs from the control sites, the difference can be assumed to be due to the treatment.

A potential weakness of cross-sectional studies is that the treatment and control sites should be similar. If comparable control sites cannot be identified, the premise of cross-sectional studies fails. This is particularly true since many agencies treat high crash locations which may look similar to control intersections which have similar characteristics but are not high crash locations. A before and after study can highlight these differences which is lacking in a crosssectional study. This study used propensity scores to select the best matching treatment and controls pairs.

The presence of treatment or stop-sign mounted beacons is associated with a $3 \%-46 \%$ increase in daytime crashes across all severity models. This suggests that beacons were likely installed at high crash locations. Presence of stop-sign mounted beacons is associated with a $5 \%-54 \%$ reduction in nighttime crashes. More desirably injury nighttime crashes decreased by $54 \%$ (statistically significantly at 0.1 alpha level) and total nighttime crashes reduced by $18 \%$. Property damage crashes were reduced by $5 \%$. These results signify that the treatment have potential for decreasing severe crashes. Results suggest that use of stop-sign mounted beacons does have potential, particularly for reduction of injury crashes.

As noted in the background section, the Iowa DOT has been moving towards use of stop-sign mounted beacons rather than overhead flashing beacons. Depending on the study and type of crash, use of overhead flashing beacons is associated with a $9 \%$ to $62 \%$ reduction in crashes although one study found no change. The study reported in this paper found nighttime crashes at locations with stop-sign mounted beacons were associated with a $3 \%$ to $46 \%$ decrease depending on type of crash and severity. Although, results for the two different countermeasures are not directly comparable, there is evidence that stop-sign 
mounted beacons are as effective in reducing night-time crashes. As a result, the study concludes that the stop-sign beacon is likely as effective as the treatment it is replacing and has the added advantage of being less likely to confuse drivers.

Additionally, the cost of installing stop sign mounted beacons is less than overhead beacons since stop-sign beacons do not require overhead wiring structures or taping into a power source. In most cases, the beacon is powered using a solar panel. Overall stop-sign mounted beacons are a reasonably low cost countermeasure which have significant potential to reduce nighttime crashes at rural intersections. This confirms the Iowa DOT's plan to continue the switch from overhead to stop-sign mounted beacons as well as considering their application in other rural intersections where nighttime crashes are problematic.

\section{Acknowledgements}

The team wishes to thank the Iowa Department of Transportation and the Midwest Transportation Center who provided funding for this project.

\section{Conflicts of Interest}

The authors declare no conflicts of interest regarding the publication of this paper.

\section{References}

[1] IIHS. Roadway and Environment. Insurance Institute for Highway Safety, Highway Loss Data Institute. http://www.iihs.org/iihs/topics/t/roadway-and-environment/fatalityfacts/roadway-a nd-environment

[2] Retting, R.A., Weinstein, H.B. and Solomon, M.G. (2003) Analysis of Motor-Vehicle Crashes at Stop Signs in Four U.S. Cities. Journal of Safety Research, 34, 485-489. https://doi.org/10.1016/j.jsr.2003.05.001

[3] Massie, D.L., Campbell, K.L. and Blower, D.F. (1993) Development of a Collision Typology for Evaluation of Collision Avoidance Strategies. Accident Analysis \& Prevention, 25, 241-257. https://doi.org/10.1016/0001-4575(93)90019-S

[4] Donell, E.T., Harwood, D.W., Bauer, K.M., Mason Jr., J.M. and Pietrucha, M.T. (2002) Cross-Median Collisions on Pennsylvania Interstates and Expressways. Transportation Research Record: Journal of the Transportation Research Board, 1784, 91-99.

[5] Harwood, D.W., Pietrucha, M.T., Wooldridge, M.D., Brydia, R.E. and Fitzpatrick, K. (1995) NCHRP Report 375: Median Intersection Design. TRB, National Research Council, Washington DC.

[6] Burchett, G.D. and Maze, T.H. (2006) Rural Expressway Intersection Characteristics as Factors in Reducing Safety Performance. Transportation Research Record: Jour nal of the Transportation Research Board, 1953, 71-80.

[7] Srinivasan, R. (March 2008) Safety Evaluation of Flashing Beacons at Stop-Controlled Intersections. U.S. Department of Transportation, Federal Highway Administration, FHWA-HRT-08-044.

[8] Murphy, B.G. and Hummer, J.E. (2007) Development of Crash Reduction Factors for Overhead Flashing Beacons at Rural Intersections in North Carolina. Transpor- 
tation Research Record: Journal of the Transportation Research Board, 2030, 15-21.

[9] Pant, P.D., Park, Y., Neti, S.V. and Hossain, A.B. (2007) Comparative Study of Rural Stop-Controlled and Beacon-Controlled Intersections. Transportation Research Record: Journal of the Transportation Research Board, 1692, 164-172. https://doi.org/10.3141/1692-17

[10] Hammer, J.B. and Tye, E.J. (1987) Overhead Yell-Red Flashing Beacons. California Department of Transportation and Federal Highway Administration, FHWA/CA/TE-87/01.

[11] Cribbins, P. and Walton, C. (1970) Traffic Signals and Overhead Flashers at Rural Intersections: Their Effectiveness in Reducing Accidents. HRB Record 325.

[12] Brewer, M.A. and Fitzpatrick, K. (2004) Preliminary Evaluations of Safety Treatments on Rural Highways I Texas. Texas Transportation Institute, FHWA/TX05/0-4048-5.

[13] Stackhouse, S. and Cassidy, P. (1996) Warning Flashers at Rural Intersections. Mn/DOT Final Report MN/RC-1998/01. Minnesota Department of Transportation.

[14] Janoff, M.S. and Hill, J.G. (1986) Effectiveness of Flashing Beacons in Reducing Accidents at a Hazardous Rural Curve. Transportation Research Board, National Research Council, Washington DC.

[15] Goswamy, A., Hallmark, S., Litteral, T. and Pawlovich, M. (2018) Safety Evaluation of Destination Lighting Treatment at Stop Controlled Cross-Intersections. Transportation Research Record: Journal of the Transportation Research Board, published online. https://doi.org/10.1177/0361198118774747

[16] Jackett, M. and Frith, W. (2013) Quantifying The Impact of Road Lighting on Road Safety-A New Zealand Study. IATSS Research, 36, 139-145.

https://doi.org/10.1016/j.iatssr.2012.09.001

[17] Bhagavathula, R., Gibbons, R. and Edwards, C. (2015) Relationship between Roadway Illuminance Level and Nighttime Rural Intersection Safety. Transportation Research Record: Journal of the Transportation Research Board, 2485, 8-15. https://doi.org/10.3141/2485-02

[18] Isebrands, H.N., Hallmark, S.L., Li, W., McDonald, T., Storm, R. and Preston, H. (2010) Roadway Lighting Shows Safety Benefits at Rural Intersections. ASCE Journal of Transportation Engineering, 136, 949-955.

[19] Donnell, E.T., Porter, R.J. and Shankar, V.N. (2010) A Framework for Estimating the Safety Effects of Roadway Lighting at Intersections. Safety Science, 48, 14361444. https://doi.org/10.1016/j.ssci.2010.06.008 